\title{
Common endpoints of generalized weak contractive mappings via separation theorem with applications
}

\author{
Sirous Moradi ${ }^{1}$, Ali P Farajzadeh ${ }^{2}$, Yeol Je $\mathrm{Cho}^{3,4^{*}}$ and Somyot Plubtieng ${ }^{5}$
}

\author{
"Correspondence: yjcho@gnu.ac.kr \\ ${ }^{3}$ Department of Mathematics \\ Education and the RINS, \\ Gyeongsang National University, \\ Jinju, 660-701, Korea \\ ${ }^{4}$ Center for General Education, \\ China Medical University, Taichung, \\ 40402, Taiwan \\ Full list of author information is \\ available at the end of the article
}

\begin{abstract}
In this paper, first, we give the separation theorem which is an extension of the separation theorem due to Jachymski and Jóźwik (J. Math. Anal. Appl. 300:147-159, 2004). Then, by using this and the related results, we prove that two generalized weak contraction multi-valued mappings have a unique common endpoint if and only if either they have the usual approximate endpoint property or they have the common approximate strict fixed point property. This result is an extension and correct version of the main result given by Khojasteh and Rakočević (Appl. Math. Lett. 25:289-293, 2012).
\end{abstract}

MSC: $47 \mathrm{H} 10 ; 54 \mathrm{C} 60$

Keywords: generalized weak contraction; endpoint; Hausdorff metric; separation theorem

\section{Introduction}

Let $(X, d)$ be a metric space and $P_{c l, b d}(X)$ be the class of nonempty closed and bounded subsets of $X$. A point $x \in X$ is called a fixed point of a multi-valued mapping $T: X \longrightarrow$ $P_{c l, b d}(X)$ if $x \in T x$. We denote $\operatorname{Fix}(T)$ the set of fixed points of the mapping $T$, that is, $\operatorname{Fix}(T)=\{x \in X: x \in T x\}$.

An element $x \in X$ is said to be an endpoint of a multi-valued mapping $T$ if $T x=\{x\}$. We denote the set of all endpoints of $T$ by $\operatorname{End}(T)$.

Obviously, $\operatorname{End}(T) \subseteq \operatorname{Fix}(T)$. The investigations on the existence of the endpoints for multi-valued mappings have been studied in recent years by many authors; see for example [1-9] and the references therein.

In 2010, Amini-Harandi [1] proved that, under sufficient conditions, the weak contractive mapping $T$ has a unique endpoint if and only if $T$ has the approximate endpoint property. After that, in 2011, Moradi and Khojasteh [6] could improve the result by replacing the weak contraction by a general form of weak contractive and, subsequently, this result was extended by Khojasteh and Rakočević [5] by introducing the concept of the approximate and common approximate $K$-boundary strict fixed point property. By an example, however, we show that their result is not correct and so we give the correct form of it applying a new method for its proof, by establishing a separation theorem

The paper is organized as follows.

\section{Springer}


In Section 2, we give some basic definitions and results which will be needed in the sequel.

In Section 3, we give the separation theorem for upper semi-continuous function $\psi$ : $[0,+\infty) \longrightarrow[0,+\infty)$ with $\psi(t)<t$ for all $t>0$ satisfying the condition

$$
\liminf _{t \rightarrow \infty}(t-\psi(t))>0
$$

In fact, our separation theorem is a generalization of the separation theorem due to Jachymski and Jóźwik [10].

In Section 4, we prove that the common approximate strict fixed point property and the usual approximate endpoint property are equivalent for generalized weak contraction multi-valued mappings $T, S: X \longrightarrow P_{c l, b d}(X)$.

In Section 5, we give the main part in this paper. By using the separation theorem obtained in Section 3 and the results in Section 4, we prove that two generalized weak contraction multi-valued mappings have a unique common endpoint if and only if either they have the usual approximate endpoint property or they have the common approximate strict fixed point property.

Finally, in Section 6, we give some applications to integral equations by using the main result, Theorem 5.9.

The main results of this paper extend the recent results given by Zhang and Song [11], Moradi and Khojasteh [6], Daffer and Kaneko [12], Rouhani and Moradi [13], Ćirićs theorems [14] and others.

\section{Preliminaries}

In this section, we give some definitions which are used in the sequel.

Let $(X, d)$ denote a complete metric space and $H$ be the Hausdorff metric defined by

$$
H(A, B):=\max \left\{\sup _{x \in B} d(x, A), \sup _{x \in A} d(x, B)\right\}
$$

for all $A, B \in P_{c l, b d}(X)$, where $P_{c l, b d}(X)$ denotes the set of nonempty closed bounded subsets of $X$.

Definition 2.1 ([14]) Two mappings $T, S: X \longrightarrow P_{c l, b d}(X)$ are said to be generalized weak contractive if there exists a function $\psi:[0,+\infty) \longrightarrow[0,+\infty)$ with $\psi(t)<t$ for all $t>0$ such that

$$
H(T x, S y) \leq \psi(N(x, y))
$$

for all $x, y \in X$, where

$$
N(x, y):=\max \left\{d(x, y), d(x, T x), d(y, S y), \frac{d(x, S y)+d(y, T x)}{2}\right\} .
$$

Definition $2.2([4,9])$ A mapping $T: X \longrightarrow P_{c l, b d}(X)$ is said to have the approximate endpoint property if

$$
\inf \{H(\{x\}, T x): x \in X\}=0 .
$$


Definition 2.3 Two mappings $T, S: X \longrightarrow P_{c l, b d}(X)$ said to have the usual approximate endpoint property if

$$
\inf \{\min (H(\{x\}, T x), H(\{x\}, S x)): x \in X\}=0 .
$$

Note that, if $T$ and $S$ are two single-valued mappings on $X$, then $T$ and $S$ have the usual approximate fixed point property, i.e.,

$$
\inf \{\min (d(x, T x), d(x, S x)): x \in X\}=0 .
$$

Obviously, $T$ and $S$ have the usual approximate endpoint property if and only if there exists a sequence $\left\{x_{n}\right\}$ such that

$$
\lim _{n \rightarrow \infty} H\left(\left\{x_{n}\right\}, T x_{n}\right)=0 \quad \text { or } \quad \lim _{n \rightarrow \infty} H\left(\left\{x_{n}\right\}, S x_{n}\right)=0 .
$$

Also, if at least one of $T$ or $S$ has the approximate endpoint property, then $T$ and $S$ have the usual approximate endpoint property.

Definition 2.4 Two mappings $T, S: X \longrightarrow P_{c l, b d}(X)$ are said to have the common approximate strict fixed point property if there exists a sequence $\left\{x_{n}\right\}$ such that

$$
\lim _{n \rightarrow \infty} H\left(\left\{x_{n}\right\}, T x_{n}\right)=\lim _{n \rightarrow \infty} H\left(\left\{x_{n}\right\}, S x_{n}\right)=0 .
$$

It is clear that, if $S, T$ have the common approximate strict fixed point property, then they have the usual approximate endpoint property.

Definition 2.5 Two multi-valued mappings $T, S: X \longrightarrow P_{c l, b d}(X)$ are said to have the common approximate $K$-boundary strict fixed point property if there exists a sequence $\left\{x_{n}\right\} \subset \partial K$, where $K$ is a nonempty subset of $X$ and $\partial K$ is boundary of $K$, such that

$$
\lim _{n \rightarrow \infty} H\left(\left\{x_{n}\right\}, T x_{n}\right)=\lim _{n \rightarrow \infty} H\left(\left\{x_{n}\right\}, S x_{n}\right)=0 .
$$

The concept of the approximate and common approximate $K$-boundary strict fixed point property were defined by Khojasteh and Rakočević [5].

We note that, if $T$ and $S$ have the common approximate strict fixed point property, then have the usual approximate endpoint property. But the converse is not true.

Example 2.6 Let $X=\mathbb{R}$ with the Euclidian metric. If two mappings $T, S: X \rightarrow P_{c l, b d}(X)$ defined by $T x=\{x\}$ and $S x=[x+1, x+2]$ (the closed interval between $x+1$ and $x+2$ ), respectively, then $T$ and $S$ have the usual approximate endpoint property, while they do not have the common approximate strict fixed point property.

Let $\Psi$ be the class of all upper semi-continuous functions $\psi:[0,+\infty) \longrightarrow[0,+\infty)$ with

$$
\psi(t)<t, \quad \liminf _{t \rightarrow \infty}(t-\psi(t))>0
$$


for all $t>0$. Also, let $\Phi$ denote the class of all continuous and nondecreasing functions $\varphi:[0,+\infty) \longrightarrow[0,+\infty)$ with $\varphi(t)<t$ for all $t>0$ such that there exist $\delta, M>0$ such that

$$
\varphi(t)<t-\delta
$$

for all $t \geq M$. Obviously, $\Phi \subset \Psi$.

\section{The separation theorem}

In this section, we establish a separation theorem. In order to prove it, we need the following lemma.

Lemma 3.1 Let $\psi \in \Psi$. Then, for any closed interval $[a, b] \subset(0,+\infty)$, there exists $\alpha \in(0,1)$ such that $\psi(t)<\alpha$ t for all $t \in[a, b]$.

Proof Suppose that the conclusion is not true. Assume that there exists $[a, b] \subset(0,+\infty)$ such that, for all $\alpha \in(0,1)$, there exists $t \in[a, b]$ such that $\psi(t) \geq \alpha t$. Let $\left\{\alpha_{n}\right\}$ be a sequence in $(0,1)$ with $\lim _{n \rightarrow \infty} \alpha_{n}=1$. Then, for all $n \in \mathbb{N}$, there exists $t_{n} \in[a, b]$ such that $\psi\left(t_{n}\right) \geq$ $\alpha_{n} t_{n}$. Since $\left\{t_{n}\right\} \subset[a, b]$ and $[a, b]$ is compact, there exist a subsequence $\left\{t_{n(k)}\right\}$ of $\left\{t_{n}\right\}$ and $t \in$ $[a, b]$ such that $\lim _{k \rightarrow \infty} t_{n(k)}=t$. Hence we have $\lim _{k \rightarrow \infty} \alpha_{n(k)} t_{n(k)}=t$. Also, from $\alpha_{n(k)} t_{n(k)} \leq$ $\psi\left(t_{n(k)}\right)<t_{n(k)}$, it follows that $\lim _{k \rightarrow \infty} \psi\left(t_{n(k)}\right)=t$. Since $\psi$ is upper semi-continuous, it follows that $\lim _{k \rightarrow \infty} \psi\left(t_{n(k)}\right) \leq \psi(t)$ and so $t \leq \psi(t)$, which is a contradiction (note $\psi \in \Psi$ ). This completes the proof.

Theorem 3.2 Let $\psi \in \Psi$. Then there exists $\varphi \in \Phi$ such that $\psi(t)<\varphi(t)$ for all $t>0$.

Proof It follows from $\liminf _{t \rightarrow \infty}(t-\psi(t))>0$ that there exists $\delta_{0}>0$ such that

$$
\liminf _{t \rightarrow \infty}(t-\psi(t))>\delta_{0}
$$

Hence there exists $M>0$ such that $t-\psi(t)>\delta_{0}$ for all $t \geq M$. Therefore, $\psi(t)<t-\delta_{0}$ for all $t \geq M$. Let $\left\{x_{n}\right\} \subset\left(0, M-\delta_{0}\right)$ be a decreasing sequence such that $\lim _{n \rightarrow \infty} x_{n}=0$. Using Lemma 3.1, there exists $\alpha_{1} \in(0,1)$ such that $\psi(t)<\alpha_{1} t$ for all $t \in\left[x_{1}, M\right]$ and $x_{2}<\alpha_{1} x_{1}$. Also, there exists $\alpha_{2} \in(0,1)$ such that $\psi(t)<\alpha_{2} t$ for all $t \in\left[x_{2}, x_{1}\right], \alpha_{1}<\alpha_{2}$, and $x_{3}<\alpha_{2} x_{2}$. Using induction and Lemma 3.1, there exists a sequence $\left\{\alpha_{n}\right\}$ in $(0,1)$ such that $\psi(t)<\alpha_{n} t$ for all $t \in\left[x_{n}, x_{n-1}\right], \alpha_{n-1}<\alpha_{n}$, and $x_{n+1}<\alpha_{n} x_{n}$.

Now, we define a function $\varphi:[0,+\infty) \longrightarrow[0,+\infty)$ by

$$
\varphi(t)= \begin{cases}0, & t=0, \\ \alpha_{n} x_{n}+\left(t-x_{n}\right) \frac{\alpha_{n} x_{n}-\alpha_{n+1} x_{n+1}}{x_{n}-x_{n+1}}, & t \in\left[x_{n+1}, x_{n}\right], \\ M-\delta_{0}+(t-M) \frac{M-\delta_{0}-\alpha_{1} x_{1}}{M-x_{1}}, & t \in\left[x_{1}, M\right], \\ t-\delta_{0}, & t \in[M,+\infty) .\end{cases}
$$

Obviously, $\varphi$ is continuous and nondecreasing and $\psi(t)<\varphi(t)$ for all $t>0$. Also, $\varphi(t)<t$ for all $t>0$. Therefore, $\varphi \in \Phi$. This completes the proof.

Let $\Omega$ be the class of all the functions $\psi:[0,+\infty) \longrightarrow[0,+\infty)$ such that, for some $\varphi \in \Phi$, $\psi(t)<\varphi(t)$ for all $t>0$. Obviously, $\Phi \subset \Psi \subset \Omega$. 
The following example shows that $\Phi \subsetneq \Psi \subsetneq \Omega$.

Example 3.3 Let $\psi_{1}, \psi_{2}:[0,+\infty) \longrightarrow[0,+\infty)$ defined by

$$
\psi_{1}(t)= \begin{cases}\frac{t}{3}, & t \in[0,2), \\ \frac{t}{2}, & t \in[2, \infty),\end{cases}
$$

and

$$
\psi_{2}(t)= \begin{cases}\frac{t}{3}, & t \in[0,2], \\ \frac{t}{2}, & t \in(2, \infty),\end{cases}
$$

respectively. Obviously, $\psi_{1} \in \Psi \backslash \Phi$ and $\psi_{2} \in \Omega \backslash \Psi$.

\section{The approximate endpoint property}

In this section, we prove that the common approximate strict fixed point property and the usual approximate endpoint property are equivalent for generalized weak contraction mappings $T, S: X \longrightarrow P_{c l, b d}(X)$.

The following result plays an important role reaching the main goal of this section.

Lemma 4.1 Let $\varphi \in \Phi$. Then the condition $\lim _{n \rightarrow \infty}\left(t_{n}-\varphi\left(t_{n}\right)\right)=0$ implies that $\lim _{n \rightarrow \infty} t_{n}=$ 0 .

Proof Since $\varphi \in \Phi,\left\{t_{n}\right\}$ is a bounded sequence. If $\lim _{n \rightarrow \infty} t_{n} \neq 0$, then there exist $t>0$ and a subsequence $\left\{t_{n(k)}\right\}$ such that $\lim _{k \rightarrow \infty} t_{n(k)}=t$. Using $\lim _{k \rightarrow \infty}\left(t_{n(k)}-\varphi\left(t_{n(k)}\right)\right)=0$ and the continuity of $\varphi$, we get $\varphi(t)=t$, which is a contradiction.

Theorem 4.2 Let $(X, d)$ be a complete metric space and $T, S: X \longrightarrow P_{c l, b d}(X)$ be two multivalued mappings such that

$$
H(T x, S y) \leq \psi(N(x, y))
$$

for all $x, y \in X$, i.e., generalized weak contraction, where $\psi \in \Omega$ and $\psi(0)=0$. Then $T$ and $S$ have the common approximate strict fixed point property if and only if they have the usual approximate endpoint property.

Proof It is clear that, if $T$ and $S$ have the common approximate strict fixed point property, then they have the usual approximate endpoint property.

Conversely, let $T$ and $S$ have the usual approximate endpoint property. Thus there exists a sequence $\left\{x_{n}\right\}$ such that

$$
\lim _{n \rightarrow \infty} H\left(\left\{x_{n}\right\}, T x_{n}\right)=0 \quad \text { or } \quad \lim _{n \rightarrow \infty} H\left(\left\{x_{n}\right\}, S x_{n}\right)=0 .
$$

Suppose that $\lim _{n \rightarrow \infty} H\left(\left\{x_{n}\right\}, T x_{n}\right)=0$. We need to show that $\lim _{n \rightarrow \infty} H\left(\left\{x_{n}\right\}, S x_{n}\right)=0$. Using Theorem 3.2, there exists $\varphi \in \Phi$ such that $\psi(t)<\varphi(t)$ for all $t>0$. Since $\psi(0)=0$, 
we have $\psi \leq \varphi$ on $[0,+\infty)$. Consequently, for all $n \in \mathbb{N}$, we have

$$
\begin{aligned}
H\left(\left\{x_{n}\right\}, S x_{n}\right) & \leq H\left(\left\{x_{n}\right\}, T x_{n}\right)+H\left(T x_{n}, S x_{n}\right) \\
& \leq H\left(\left\{x_{n}\right\}, T x_{n}\right)+\psi\left(N\left(x_{n}, x_{n}\right)\right) \\
& \leq H\left(\left\{x_{n}\right\}, T x_{n}\right)+\varphi\left(N\left(x_{n}, x_{n}\right)\right),
\end{aligned}
$$

where

$$
\begin{aligned}
N\left(x_{n}, x_{n}\right) & =\max \left\{d\left(x_{n}, x_{n}\right), d\left(x_{n}, T x_{n}\right), d\left(x_{n}, S x_{n}\right), \frac{d\left(x_{n}, T x_{n}\right)+d\left(x_{n}, S x_{n}\right)}{2}\right\} \\
& =\max \left\{d\left(x_{n}, T x_{n}\right), d\left(x_{n}, S x_{n}\right)\right\} .
\end{aligned}
$$

Hence we have

$$
\begin{aligned}
H\left(\left\{x_{n}\right\}, S x_{n}\right) & \leq H\left(\left\{x_{n}\right\}, T x_{n}\right)+\varphi\left(\max \left\{d\left(x_{n}, T x_{n}\right), d\left(x_{n}, S x_{n}\right)\right\}\right) \\
& \leq H\left(\left\{x_{n}\right\}, T x_{n}\right)+\varphi\left(H\left(\left\{x_{n}\right\}, T x_{n}\right)+H\left(\left\{x_{n}\right\}, S x_{n}\right)\right)
\end{aligned}
$$

and so

$$
\begin{aligned}
& H\left(\left\{x_{n}\right\}, T x_{n}\right)+H\left(\left\{x_{n}\right\}, S x_{n}\right) \\
& \quad \leq 2 H\left(\left\{x_{n}\right\}, T x_{n}\right)+\varphi\left(H\left(\left\{x_{n}\right\}, T x_{n}\right)+H\left(\left\{x_{n}\right\}, S x_{n}\right)\right) .
\end{aligned}
$$

Therefore, we have

$$
\begin{aligned}
& H\left(\left\{x_{n}\right\}, T x_{n}\right)+H\left(\left\{x_{n}\right\}, S x_{n}\right)-\varphi\left(H\left(\left\{x_{n}\right\}, T x_{n}\right)+H\left(\left\{x_{n}\right\}, S x_{n}\right)\right) \\
& \quad \leq 2 H\left(\left\{x_{n}\right\}, T x_{n}\right) .
\end{aligned}
$$

Thus we have

$$
\lim _{n \rightarrow \infty}\left(H\left(\left\{x_{n}\right\}, T x_{n}\right)+H\left(\left\{x_{n}\right\}, S x_{n}\right)\right)-\varphi\left(H\left(\left\{x_{n}\right\}, T x_{n}\right)+H\left(\left\{x_{n}\right\}, S x_{n}\right)\right)=0
$$

and so, by applying Lemma 4.1, we deduce that $\lim _{n \rightarrow \infty} H\left(\left\{x_{n}\right\}, T x_{n}\right)+H\left(\left\{x_{n}\right\}, S x_{n}\right)=0$. Therefore $\lim _{n \rightarrow \infty} H\left(\left\{x_{n}\right\}, S x_{n}\right)=0$. This completes the proof.

\section{The endpoint and fixed point results}

The main motivation for this section is to present an exact version and correct proof for the following theorem.

Theorem $5.1([5])$ Let $(X, d)$ be a complete metric space and $K$ be a closed subset of $X$. Suppose that $T, S: X \longrightarrow P_{c l, b d}(X)$ are two multi-valued mappings such that

$$
H(T x, S y) \leq \psi(N(x, y))
$$

for all $x, y \in X$, where

$$
N(x, y):=\max \left\{d(x, y), d(x, T x), d(y, S y), \frac{d(x, S y)+d(y, T x)}{2}\right\}
$$


and $\psi:[0,+\infty) \longrightarrow[0,+\infty)$ is upper semi-continuous with

$$
\psi(t)<t, \quad \liminf _{t \rightarrow \infty}(t-\psi(t))>0
$$

for all $t>0$. Then two mappings $T, S$ have a unique common strict fixed point in $K$ if and only if they have the common approximate K-boundary strict fixed point property. Also, $\operatorname{End}(T)=\operatorname{Fix}(T)=\operatorname{Fix}(S)=\operatorname{End}(S)$.

The following example shows that the aforementioned theorem is not correct.

Example 5.2 Let $X=\mathbb{R}$ be endowed with the Euclidian metric, $K=[-1,+1]$ and $T, S$ : $K \longrightarrow P_{b d, c l}(X)$ defined by $T x=S x=\left\{\frac{x}{2}\right\}$. Obviously, $\partial K=\{-1,+1\}$. We define the mapping $\psi:[0,+\infty) \longrightarrow[0,+\infty)$ by $\psi(t)=\frac{t}{2}$. One can show that all hypotheses in Theorem 5.1 hold. Also $T, S$ have a unique common endpoint $x=0$ in $K$. But $T$ and $S$ do not have the common approximate $K$-boundary strict fixed point property.

The following theorem is a modification and generalization form of the above theorem which is the most important consequence of this article.

Theorem 5.3 Let $(X, d)$ be a complete metric space and let $T, S: X \longrightarrow P_{c l, b d}(X)$ be two multi-valued mappings such that

$$
H(T x, S y) \leq \psi(N(x, y))
$$

for all $x, y \in X$ (i.e., a generalized weak contraction), where $\psi \in \Omega$. Then $T$ and $S$ have a unique common endpoint if and only if at least one of the following holds:

(1) $\psi(0)=0$ and $T$ and $S$ have the usual approximate endpoint property.

(2) $T$ and $S$ have the common approximate strict fixed point property.

Proof It is clear that, if $T$ and $S$ have a common endpoint, then they have the common approximate strict fixed point property.

Conversely, let one of the conditions (1) and (2) hold. Hence, by Theorem 4.2, there exists a sequence $\left\{x_{n}\right\}$ such that

$$
\lim _{n \rightarrow \infty} H\left(\left\{x_{n}\right\}, T x_{n}\right)=\lim _{n \rightarrow \infty} H\left(\left\{x_{n}\right\}, S x_{n}\right)=0 .
$$

Using Theorem 3.2, there exists $\varphi \in \Phi$ such that $\psi(t)<\varphi(t)$ for all $t>0$. It follows that, for all $m, n \in \mathbb{N}$,

$$
\begin{aligned}
N\left(x_{m}, x_{n}\right) & \leq H\left(\left\{x_{m}\right\},\left\{x_{n}\right\}\right)+H\left(\left\{x_{m}\right\}, T x_{m}\right)+H\left(\left\{x_{n}\right\}, S x_{n}\right) \\
& \leq H\left(T x_{m}, S x_{n}\right)+2 H\left(\left\{x_{m}\right\}, T x_{m}\right)+2 H\left(\left\{x_{n}\right\}, S x_{n}\right) \\
& \leq \psi\left(N\left(x_{m}, x_{n}\right)\right)+2 H\left(\left\{x_{m}\right\}, T x_{m}\right)+2 H\left(\left\{x_{n}\right\}, S x_{n}\right) \\
& \leq \varphi\left(N\left(x_{m}, x_{n}\right)\right)+2 H\left(\left\{x_{m}\right\}, T x_{m}\right)+2 H\left(\left\{x_{n}\right\}, S x_{n}\right)
\end{aligned}
$$

and so

$$
0 \leq N\left(x_{m}, x_{n}\right)-\varphi\left(N\left(x_{m}, x_{n}\right)\right) \leq 2 H\left(\left\{x_{m}\right\}, T x_{m}\right)+2 H\left(\left\{x_{n}\right\}, S x_{n}\right) .
$$


Obviously, if $N\left(x_{m}, x_{n}\right)=0$, then the inequality (5.6) is true. Thus it follows from (5.6) and (5.4) that

$$
\lim _{n, m \rightarrow \infty}\left(N\left(x_{m}, x_{n}\right)-\varphi\left(N\left(x_{m}, x_{n}\right)\right)\right)=0
$$

and so, from Lemma 4.1, it follows that

$$
\lim _{n, m \rightarrow \infty} N\left(x_{m}, x_{n}\right)=0
$$

and so $\left\{x_{n}\right\}$ is a Cauchy sequence (note $d\left(x_{m}, x_{n}\right) \leq N\left(x_{m}, x_{n}\right)$ ) and then there exists $x \in X$ such that $\lim _{n \rightarrow \infty} x_{n}=x$.

Now, we show that $T x=S x=\{x\}$. In fact, if there exists a subsequence $\left\{x_{n(k)}\right\}$ of $\left\{x_{n}\right\}$ such that $x_{n(k)}=x$ for all $k \in \mathbb{N}$. Then, from (5.4), it follows that $\lim _{k \rightarrow \infty} H\left(\left\{x_{n(k)}\right\}, T x_{n(k)}\right)=$ $\lim _{n \rightarrow \infty} H\left(\left\{x_{n(k)}\right\}, S x_{n(k)}\right)=0$ implies that

$$
H(\{x\}, T x)=H(\{x\}, S x)=0
$$

and hence $T x=S x=\{x\}$. So, we may assume that, for all $n \in \mathbb{N}, x_{n} \neq x$. Hence, for all $n \in \mathbb{N}$, $N\left(x_{n}, x\right) \neq 0$. Thus, for all $n \in \mathbb{N}$, we have $\psi\left(N\left(x_{n}, x\right)\right)<\varphi\left(N\left(x_{n}, x\right)\right)$. Therefore, we have

$$
\begin{aligned}
d\left(x_{n}, S x\right) & \leq H\left(\left\{x_{n}\right\}, S x\right) \leq H\left(\left\{x_{n}\right\}, T x_{n}\right)+H\left(T x_{n}, S x\right) \\
& \leq H\left(\left\{x_{n}\right\}, T x_{n}\right)+\psi\left(N\left(x_{n}, x\right)\right) \\
& <H\left(\left\{x_{n}\right\}, T x_{n}\right)+\varphi\left(N\left(x_{n}, x\right)\right)
\end{aligned}
$$

for all $n \in \mathbb{N}$. Since $\varphi$ is continuous and $\lim _{n \rightarrow \infty} N\left(x_{n}, x\right)=d(x, S x)$, it follows from (5.7) that

$$
d(x, S x) \leq H(\{x\}, S x) \leq \varphi(d(x, S x)) .
$$

Since $\varphi(t)<t$ for all $t>0$ and (5.8) holds, we have $d(x, S x)=0$ and hence $H(\{x\}, S x)=0$. Thus $S x=\{x\}$.

Similarly, $T x=\{x\}$. Therefore, $T$ and $S$ have a common endpoint.

The uniqueness of the common endpoint follows from (5.3). This completes the proof.

Corollary 5.4 Let $(X, d)$ be a complete metric space and $T: X \longrightarrow P_{c l, b d}(X)$ be a multivalued mapping such that

$$
H(T x, T y) \leq \psi(N(x, y))
$$

for all $x, y \in X$, i.e., a weak contraction, where $\psi \in \Omega$. Then $T$ has a unique endpoint if and only if $T$ has the approximate endpoint property.

Proof If $T$ has a unique endpoint, then $T$ has the approximate endpoint property.

Conversely, let $T$ have the approximate endpoint property. Define $S=T$. Then $T$ and $S$ have the common approximate strict fixed point property. Hence, using Theorem 5.3, $T$ has a unique endpoint. 
Corollary 5.5 Let $(X, d)$ be a complete metric space and $T, S: X \longrightarrow P_{c l, b d}(X)$ be two mappings such that, for all $x, y \in X$,

$$
H(T x, S y) \leq k N(x, y)
$$

for some $0 \leq k<1$, i.e., weak contraction. Then $T$ and $S$ have a unique common endpoint if and only if they have the common approximate strict fixed point property.

Proof Let $\psi(t)=k t$ and apply Theorem 5.3.

The following corollary extends the results given by Nadler [15], Daffer and Kaneko [12] and Rouhani and Moradi [13].

Corollary 5.6 Let $(X, d)$ be a complete metric space and $T, S: X \longrightarrow P_{c l, b d}(X)$ be two mappings such that, for all $x, y \in X$,

$$
H(T x, S y) \leq k N(x, y)
$$

for some $0 \leq k<1$. Then there exists a point $x \in X$ such that $x \in T x$ and $x \in S x$, i.e., $T$ and $S$ have a common fixed point. Also, if $T$ and $S$ have the usual approximate endpoint property, then $\operatorname{Fix}(T)=\operatorname{Fix}(S)=\operatorname{End}(T)=\operatorname{End}(S)=\{x\}$, and so the fixed point is unique.

Proof Using Theorem 3.1 of Rouhani and Moradi [13], there exists $x \in X$ such that $x \in T x$ and $x \in S x$. Also, from (5.11), we conclude that $\operatorname{Fix}(T)=\operatorname{Fix}(S)$. If $T$ and $S$ have the usual approximate endpoint property, by Corollary 5.5, we conclude that $T$ and $S$ have a unique endpoint $x_{0}$. So $\operatorname{End}(T)=\operatorname{End}(S)=\left\{x_{0}\right\}$.

Now, we need to show that, for all $y \in \operatorname{Fix}(T)=\operatorname{Fix}(S), y=x_{0}$. If $y \in \operatorname{Fix}(T)=\operatorname{Fix}(S)$, then it follows from $d\left(x_{0}, y\right) \leq H\left(\left\{x_{0}\right\}, S y\right)$ that

$$
d\left(x_{0}, y\right) \leq H\left(\left\{x_{0}\right\}, S y\right)=H\left(T x_{0}, S y\right) \leq k N\left(x_{0}, y\right) .
$$

Since $d\left(x_{0}, S y\right) \leq d\left(x_{0}, y\right), d\left(y, T x_{0}\right) \leq d\left(y, x_{0}\right)$ and $y \in \operatorname{Fix}(S)$, we have

$$
\begin{aligned}
N\left(x_{0}, y\right) & =\max \left\{d\left(x_{0}, y\right), d\left(x_{0}, T x_{0}\right), d(y, S y), \frac{d\left(x_{0}, S y\right)+d\left(y, T x_{0}\right)}{2}\right\} \\
& =d\left(x_{0}, y\right) .
\end{aligned}
$$

Thus, from (5.13), we conclude that $d\left(x_{0}, y\right) \leq k d\left(x_{0}, y\right)$. This shows that $d\left(x_{0}, y\right)=0$. Therefore, $y=x_{0}$. This completes the proof.

The following corollary is a direct result of Theorem 5.3.

Corollary 5.7 Let $(X, d)$ be a complete metric space and $f, g: X \longrightarrow X$ be two mappings such that, for all $x, y \in X$,

$$
d(f(x), g(y)) \leq \psi(N(x, y))
$$

where $\psi \in \Omega$. Then $f$ and $g$ have a unique common fixed point if and only if they have the usual approximate fixed point property. 
Proof There exists $\varphi \in \Phi$ such that $\psi(t)<\psi(t)$ for all $t>0$. It is clear that, if $f$ and $g$ have a unique fixed point, then $f$ and $g$ have the usual approximate endpoint property.

Conversely, let $f$ and $g$ have the usual approximate fixed point property. Hence there exists a sequence $\left\{x_{n}\right\}$ such that $\lim _{n \rightarrow \infty} d\left(x_{n}, f\left(x_{n}\right)\right)=0$ or $\lim _{n \rightarrow \infty} d\left(x_{n}, g\left(x_{n}\right)\right)=0$. Suppose that $\lim _{n \rightarrow \infty} d\left(x_{n}, f\left(x_{n}\right)\right)=0$.

Now, we prove that, for some subsequence $\left\{x_{n(k)}\right\}$ of $\left\{x_{n}\right\}$,

$$
\lim _{k \rightarrow \infty} d\left(x_{n(k)}, g\left(x_{n(k)}\right)\right)=0 .
$$

If there exists a subsequence $\left\{x_{n(k)}\right\}$ such that $x_{n(k)}=g\left(x_{n(k)}\right)$, then $\lim _{k \rightarrow \infty} d\left(x_{n(k)}\right.$, $\left.g\left(x_{n(k)}\right)\right)=0$. So, we may assume that there exists $N_{0} \in \mathbb{N}$ such that $x_{n} \neq g\left(x_{n}\right)$ for all $n \geq N_{0}$. Thus, for all $n \geq N_{0}, N\left(x_{n}, g\left(x_{n}\right)\right) \neq 0$ and hence $\psi\left(N\left(x_{n}, x_{n}\right)\right)<\varphi\left(N\left(x_{n}, x_{n}\right)\right)$. Therefore, it follows that, for all $n \geq N_{0}$,

$$
\begin{aligned}
d\left(x_{n}, g\left(x_{n}\right)\right) & \leq d\left(x_{n}, f\left(x_{n}\right)\right)+d\left(f\left(x_{n}\right), g\left(x_{n}\right)\right) \\
& \leq d\left(x_{n}, f\left(x_{n}\right)\right)+\psi\left(N\left(x_{n}, x_{n}\right)\right) \\
& <d\left(x_{n}, f\left(x_{n}\right)\right)+\varphi\left(N\left(x_{n}, x_{n}\right)\right) \\
& \leq d\left(x_{n}, f\left(x_{n}\right)\right)+\varphi\left(d\left(x_{n}, f\left(x_{n}\right)\right)+d\left(x_{n}, g\left(x_{n}\right)\right)\right) .
\end{aligned}
$$

Hence we have

$$
\begin{aligned}
0 & \leq d\left(x_{n}, f\left(x_{n}\right)\right)+d\left(x_{n}, g\left(x_{n}\right)\right)-\varphi\left(d\left(x_{n}, f\left(x_{n}\right)\right)+d\left(x_{n}, g\left(x_{n}\right)\right)\right) \\
& \leq 2 d\left(x_{n}, f\left(x_{n}\right)\right),
\end{aligned}
$$

which shows that

$$
\lim _{n \rightarrow \infty}\left(d\left(x_{n}, f\left(x_{n}\right)\right)+d\left(x_{n}, g\left(x_{n}\right)\right)-\varphi\left(d\left(x_{n}, f\left(x_{n}\right)\right)+d\left(x_{n}, g\left(x_{n}\right)\right)\right)\right)=0 .
$$

So, it follows from Lemma 4.1 that

$$
\lim _{n \rightarrow \infty} d\left(x_{n}, f\left(x_{n}\right)\right)+d\left(x_{n}, g\left(x_{n}\right)\right)=0
$$

and hence $\lim _{n \rightarrow \infty} d\left(x_{n}, g\left(x_{n}\right)\right)=0$. Therefore, $f$ and $g$ have the common approximate strict fixed point property.

Using Theorem 5.3, $f$ and $g$ have a unique common fixed point. This completes the proof.

Theorem 5.8 Let $(X, d)$ be a complete metric space and $f, g: X \longrightarrow X$ be two mappings such that, for all $x, y \in X$,

$$
d(f(x), g(y)) \leq \psi(N(x, y))
$$

where $\psi \in \Omega$. Then $f$ and $g$ have the usual approximate fixed point property. 
Proof There exists $\varphi \in \Phi$ such that $\psi(t)<\varphi(t)$ for all $t>0$ and so, for all $x \neq y$,

$$
d(f(x), g(y)) \leq \varphi(N(x, y)) .
$$

Now, if $N(x, y)=0$, then it follows from (5.17) and $\psi(0)=0$ that $x=y=f(x)=g(y)$ and hence the inequality (5.18) is valid for all $x, y \in X$. Let

$$
\begin{aligned}
& x_{0} \in X, \quad x_{1}=f\left(x_{0}\right), \quad x_{2}=g\left(x_{1}\right), \quad \ldots, \\
& x_{2 n+1}=f\left(x_{2 n}\right), \quad x_{2 n+2}=g\left(x_{2 n+1}\right), \quad \ldots .
\end{aligned}
$$

It follows from (5.18) that, for all $n \in \mathbb{N}$,

$$
d\left(x_{2 n+1}, x_{2 n}\right) \leq \varphi\left(N\left(x_{2 n}, x_{2 n-1}\right)\right)
$$

where

$$
\begin{aligned}
N & \left(x_{2 n}, x_{2 n-1}\right) \\
& =\max \left\{d\left(x_{2 n}, x_{2 n-1}\right), d\left(x_{2 n}, x_{2 n+1}\right), d\left(x_{2 n-1}, x_{2 n}\right), \frac{d\left(x_{2 n}, x_{2 n}\right)+d\left(x_{2 n-1}, x_{2 n+1}\right)}{2}\right\} \\
& \leq \max \left\{d\left(x_{2 n}, x_{2 n-1}\right), d\left(x_{2 n}, x_{2 n+1}\right), \frac{d\left(x_{2 n-1}, x_{2 n}\right)+d\left(x_{2 n}, x_{2 n+1}\right)}{2}\right\} \\
& =\max \left\{d\left(x_{2 n}, x_{2 n-1}\right), d\left(x_{2 n}, x_{2 n+1}\right)\right\} .
\end{aligned}
$$

If $d\left(x_{2 n}, x_{2 n-1}\right)<d\left(x_{2 n}, x_{2 n+1}\right)$, then it follows from (5.19) and (5.20) that

$$
d\left(x_{2 n+1}, x_{2 n}\right) \leq \varphi\left(d\left(x_{2 n}, x_{2 n+1}\right)\right)
$$

which is a contradiction. So, we have $d\left(x_{2 n}, x_{2 n-1}\right) \geq d\left(x_{2 n}, x_{2 n+1}\right)$. Therefore, it follows from (5.19) and (5.20) that

$$
d\left(x_{2 n+1}, x_{2 n}\right) \leq \varphi\left(d\left(x_{2 n}, x_{2 n-1}\right)\right) .
$$

Similarly, we have

$$
d\left(x_{2 n+1}, x_{2 n+2}\right) \leq \varphi\left(d\left(x_{2 n}, x_{2 n+1}\right)\right) .
$$

Hence it follows that, for all $n \in \mathbb{N}$,

$$
d\left(x_{n+1}, x_{n}\right) \leq \varphi\left(d\left(x_{n}, x_{n-1}\right)\right) .
$$

Since $\varphi(t)<t$ for all $t>0$, from (5.23), we deduce that $\left\{d\left(x_{n+1}, x_{n}\right)\right\}$ is monotone nonincreasing and bounded. So, there exists $r \geq 0$ such that $\lim _{n \rightarrow \infty} d\left(x_{n+1}, x_{n}\right)=r$. It follows from $\varphi \in \Phi$ and the inequality (5.23) that $r=0$. Hence we have

$$
\lim _{n \rightarrow \infty} d\left(x_{2 n}, f\left(x_{2 n}\right)\right)=\lim _{n \rightarrow \infty} d\left(x_{2 n}, x_{2 n+1}\right)=0 .
$$


Therefore, $f$ and $g$ have the common usual approximate fixed point property. This completes the proof.

As an application of Corollary 5.7 and Theorem 5.8, we obtain the following fixed point result, which extends the Cirić theorem [14], Theorem 2.5.

Theorem 5.9 Let $(X, d)$ be a complete metric space and $f, g: X \longrightarrow X$ be two mappings such that, for all $x, y \in X$,

$$
d(f(x), g(y)) \leq \psi(N(x, y))
$$

where $\psi \in \Omega$. Then $f$ and $g$ have a unique common fixed point.

Using Theorem 5.9, we can conclude to the corresponding theorem given by Zhang and Song [11].

Theorem 5.10 Let $(X, d)$ be a complete metric space and $f, g: X \rightarrow X$ be two mappings such that, for all $x, y \in X$,

$$
d(f(x), g(y)) \leq N(x, y)-\varphi(N(x, y))
$$

i.e. generalized $\varphi$-weak contractions, where $\varphi:[0,+\infty) \longrightarrow[0,+\infty)$ is a nondecreasing and lower semi-continuous function with $\varphi(0)=0$ and $\varphi(t)>0$ for all $t>0$. Then there exists $a$ unique point $x \in X$ such that $x=f x=g x$.

Proof Let $\psi(t)=t-\varphi(t)$ and apply Theorem 5.9.

Example 5.11 Let $X=\mathbb{C}$ be endowed with the Euclidian metric and $f, g: X \longrightarrow X$ defined by

$$
f(x+i y)=\frac{x}{3}, \quad g(x+i y)=i \frac{y}{5} .
$$

For every $x+i y, u+i v \in X$

$$
\begin{aligned}
|f(x+i y)-g(u+i v)| & =\left|\frac{x}{3}-i \frac{v}{5}\right|=\sqrt{\frac{x^{2}}{9}+\frac{v^{2}}{25}} \\
& \leq \frac{1}{3} \sqrt{x^{2}+v^{2}} \leq \frac{1}{3}\left(\sqrt{x^{2}}+\sqrt{v^{2}}\right) \\
& \leq \frac{2}{3} \frac{|(x+i y)-g(u+i v)|+|(u+i v)-f(x+i y)|}{2} \\
& \leq \frac{2}{3} N(x, y) .
\end{aligned}
$$

Hence, by using Theorem 5.9, $f$ and $g$ have a unique common fixed point. 


\section{Applications to integral equations}

Fixed point theorems in complete metric spaces are widely investigated and have found various applications in differential and integral equations. Motivated by [16], we study the existence of solutions for a system of nonlinear integral equations using the results proved in the previous section.

Theorem 6.1 Let $X=C([a, b], \mathbb{R})$ and $d: X \times X \longrightarrow \mathbb{R}$ be a mapping defined by

$$
d(x, y):=\sup \{|x(t)-y(t)|: t \in[a, b]\} .
$$

Consider the Urysohn integral equations

$$
\left\{\begin{array}{l}
x(t)=\int_{a}^{b} K_{1}(t, s, x(s)) d s+g(t), \\
x(t)=\int_{a}^{b} K_{2}(t, s, x(s)) d s+h(t),
\end{array}\right.
$$

where $t \in[a, b]$ and $x, g, h \in X$. Suppose that $K_{1}, K_{2}:[a, b] \times[a, b] \times \mathbb{R} \longrightarrow \mathbb{R}$ are two functions such that $F(x), G(x) \in X$ for all $x \in X$, where

$$
F(x)(t)=\int_{a}^{b} K_{1}(t, s, x(s)) d s+g(t), \quad G(x)(t)=\int_{a}^{b} K_{2}(t, s, x(s)) d s+h(t)
$$

for all $t \in[a, b]$. If there exists $0<\alpha<1$ such that, for all $x, y \in X$ and $t \in[a, b]$,

$$
|F(x)(t)-G(y)(t)| \leq \alpha M(x, y)(t),
$$

where

$$
\begin{aligned}
& M(x, y)(t) \\
& \quad \in\left\{|x(t)-y(t)|,|x(t)-F(x)(t)|,|y(t)-G(y)(t)|, \frac{|x(t)-G(y)(t)|+|y(t)-F(x)(t)|}{2}\right\} .
\end{aligned}
$$

Then the system of equations (6.1) has a unique common solution.

Proof It is clear that $(X, d)$ is a complete metric space. For all $x, y \in X$,

$$
d(F(x), G(y))=\sup _{t \in[a, b]}|F(x)(t)-G(y)(t)| \leq \alpha \sup _{t \in[a, b]} M(x, y)(t) \leq \alpha N(x, y) .
$$

Hence, by Theorem 5.9, $F$ and $G$ have a common fixed point. Therefore, the Urysohn integral equations (6.1) have a unique common solution. This completes the proof.

Competing interests

The authors declare that they have no competing interest.

\section{Authors' contributions}

All authors read and approved the final manuscript.

\section{Author details}

${ }^{1}$ Department of Mathematics, Faculty of Science, Arak University, Arak, 38156-8-8349, Iran. ${ }^{2}$ Department of Mathematics, Faculty of Science, Razi University, Kermanshah, 67149-67346, Iran. ${ }^{3}$ Department of Mathematics Education and the RINS, Gyeongsang National University, Jinju, 660-701, Korea. ${ }^{4}$ Center for General Education, China Medical University, Taichung, 40402, Taiwan. ${ }^{5}$ Department of Mathematics, Faculty of Science, Naresuan University, Phitsanulok, 65000, Thailand. 


\section{Acknowledgements}

The third author was supported by Basic Science Research Program through the National Research Foundation of Korea (NRF) funded by the Ministry of Science, ICT and future Planning (2014R1A2A2A01002100).

Received: 30 April 2015 Accepted: 27 October 2015 Published online: 04 November 2015

\section{References}

1. Amini-Harandi, A: Endpoints of set-valued contractions in metric spaces. Nonlinear Anal. 72, 132-134 (2010)

2. Chifu, C, Petrusel, G: Existence and data dependence of fixed points and strict fixed points for contractive-type multivalued operators. Fixed Point Theory Appl. 2007, 034248 (2007)

3. Fakhar, M: Endpoints of set-valued asymptotic contractions in metric spaces. Appl. Math. Lett. 24, $428-431$ (2011)

4. Hussain, N, Amini-Harandi, A, Cho, YJ: Approximate endpoints for set-valued contractions in metric spaces. Fixed Point Theory Appl. 2010, 614867 (2010)

5. Khojasteh, F, Rakočević, V: Some new common fixed point results for generalized contractive multi-valued non-self-mappings. Appl. Math. Lett. 25, 287-293 (2012)

6. Moradi, S, Khojasteh, F: Endpoints of multi-valued generalized weak contraction mappings. Nonlinear Anal. 74 2170-2174 (2011)

7. Wardowski, D: Endpoints and fixed points of a set-valued contractions in cone metric spaces. Nonlinear Anal. 71, 512-516 (2009)

8. Lodarczyk, KW, Klim, D, Plebaniak, R: Existence and uniqueness of endpoints of closed set-valued asymptotic contractions in metric spaces. J. Math. Anal. Appl. 328, 46-57 (2007)

9. Lodarczyk, KW, Klim, D, Plebaniak, R: Endpoint theory for set-valued nonlinear asymptotic contractions with respect to generalized pseudodistances in uniform spaces. J. Math. Anal. Appl. 339, 344-358 (2008)

10. Jachymski, J, Jóźwik, I: On Kirk's asymptotic contraction. J. Math. Anal. Appl. 300, 147-159 (2004)

11. Zhang, Q, Song, Y: Fixed point theory for generalized $\varphi$-weak contractions. Appl. Math. Lett. 22, 75-78 (2009)

12. Daffer, PZ, Kaneko, H: Fixed points of generalized contractive multi-valued mappings. J. Math. Anal. Appl. 192 655-666 (1995)

13. Rouhani, BD, Moradi, S: Common fixed point of multivalued generalized $\phi$-weak contractive mappings. Fixed Point Theory Appl. 2010, 708984 (2010)

14. Ćirić, LB: Generalized contraction and fixed point theorems. Publ. Inst. Math. (Belgr.) 12, 19-26 (1971)

15. Nadler, SB: Multi-valued contraction mappings. Pac. J. Math. 30, 475-488 (1969)

16. Hussain, N, Azamb, A, Ahmadb, J, Arshadc, M: Common fixed point results in complex valued metric spaces with application to integral equations. Filomat 28, 1363-1380 (2014)

\section{Submit your manuscript to a SpringerOpen ${ }^{\ominus}$ journal and benefit from:}

- Convenient online submission

- Rigorous peer review

- Immediate publication on acceptance

Open access: articles freely available online

High visibility within the field

- Retaining the copyright to your article 